\title{
A Selection of Electrical Machine as an Electromechanical Battery for Earth Orbit Satellite
}

\author{
M. A. L. Bader \\ Electric Power and Machine \\ department \\ Ain Shams University. \\ Cairo, Egypt
}

\author{
Ahmed M .Atallah \\ Electric Power and Machine \\ department \\ Ain Shams University. \\ Cairo, Egypt
}

\author{
Mahmoud M. Kashef \\ Electric Power and Machine \\ department \\ Ain Shams University. \\ Cairo, Egypt
}

\begin{abstract}
Many type of electrical machine can be used as an electromechanical battery for low earth orbit satellite.

Electromechanical battery is motor generator mode coupling with flywheel which used to store kinetic energy in motor mode during sunlight and supply electrical power from the stored kinetic energy by generator mode during eclipse.
\end{abstract}

Permanent magnet synchronous machine has proved to be a good candidate for its performance which achieves a requirement of electromechanical battery.

More than one configuration among Permanent magnet synchronous machine have been presented to choose between them for satellite battery the choice depend on which one has a better performance

Also paper presents aspect of the design solution of permanent magnet synchronous machine (PMSM) and selections of material such as carbon AS4C for flywheel which will achieve the required high energy storage with minimum flywheel diameter and weight compared with other designs we describe the formatting guidelines for IJCA Journal Submission.

\section{Symbol and Nomenclature}

$\begin{array}{ll}\mathrm{E} & \begin{array}{l}\text { kinetic energy stored } \\ \mathrm{I}\end{array} \\ \omega & \text { moment of inertia } \\ \rho & \text { angular velocity } \\ \mathrm{Z} & \text { axial length of the cylinder } \\ \mathrm{r}_{\mathrm{o}}, \mathrm{r}_{\mathrm{i}} & \text { outer and inner radius } \\ \mathrm{M}_{\mathrm{n}} & \text { magnetic vector } \\ \mathrm{R}_{6}, \mathrm{R}_{4}, \mathrm{R}_{5} & \text { outer radius of the stator ,the } \\ \text { radii before and after permanent magnet exciter } \\ \mu \mathrm{r}, \mu \mathrm{m} & \text { air gap and Iron permeability } \\ \mathrm{p} & \text { number of pole pair } \\ \mathrm{Br} & \text { magnet remnant } \\ \alpha \mathrm{p} & \text { PM arc to pole pitch ratio } \\ \mathrm{N} & \text { coil number of turns } \\ \mathrm{K} \alpha & \text { first harmonic coefficient } \\ \mathrm{Nt} & \text { number of tooth } \\ \mathrm{R}_{\mathrm{p}}, \mathrm{R}_{\mathrm{t}} & \text { Air gap reluctance front of } \\ \text { poleand tooth } & \text { thickness of rotor and stator } \\ \mathrm{Wt}, \mathrm{Wy} & \\ \text { material } & \text { filling factor and necessary } \\ \mathrm{ff}, \mathrm{Kcu} & \text { the time duration during } \\ \text { cupper area to flow one ampere of current } \\ \mathrm{t}\end{array}$

permanent magnetic, ferromagnetic and flywheel material

\section{Keywords}

Mechanical batteries, surface permanent magnet machine, Inset permanent magnet machine, Buried permanent magnet machine and Halbach array machine.

\section{INTRODUCTION}

Flywheel energy storage or EMB present by NASA [1] and it is used recently specially in LEO satellites. LEO satellites usually include micro satellite which rotates around the earth for a period ranging from some minutes to few hours [2].

The most critical part of these satellites is their batteries. They have limited life because of fast charge/discharge rate, thermal dependency, having more size, and need for large solar array for power storage.

The advantages of Electromechanical battery (EMB) [3-6] are unlimited charge/discharge cycle as well as satellite life time, They are more efficient, have more energy density, more discharge depths, thermal independence, no voltage sag over life, they also match well with peak power tracking of solar array, have much higher specific energy, easy charge/discharge control as the stored energy depends on the wheel speed alone and hence lower mass and volume, In [3]they used inner rotor so they did not achieve the higher energy stored in the larger outer radius rotor, ,4] did not specify the type of material used in the proposed flywheel .also ,they did not the actual position of used PM , [5] discusses the flywheel characteristic without specifying the effect of the design on the machine performance.

In this paper, a design of EMB using new material to fit in LEO satellite needs. Also, a comparison between different configurations of PM position for EMB designs is performed.

\section{FLYWHEEL PRINCIPLE}

The energy storage in a flywheel system is given by

$\mathrm{E}=\frac{1}{2} \mathrm{I} \omega^{2}$

The moment of inertia is a function of its shape and mass, given by equation

$\mathrm{dI}=\mathrm{dm} \cdot \mathrm{r}^{2}$

For the common solid cylinder, the expression for I is given on (3), where, and.

$\mathrm{I}=\frac{1}{2} \cdot \mathrm{r}^{4} \cdot \pi \cdot \mathrm{Z} \cdot \rho$

The other dominating shape is a hallow circular cylinder, approximating a composite or steel rim attached to a shaft with a web, that results in (4)

$\mathrm{I}=\frac{1}{2} \cdot \pi \cdot \mathrm{Z} \cdot \rho \cdot\left(\mathrm{r}_{\mathrm{o}}^{4}-\mathrm{r}_{\mathrm{i}}^{4}\right)$ 
The energy that can be stored in a flywheel system as a function of its speed and inner and outer radius is given by;

$\mathrm{E}=\frac{1}{4} \cdot \pi \cdot \mathrm{Z} \cdot \rho \cdot\left(\mathrm{r}_{\mathrm{o}}^{4}-\mathrm{r}_{\mathrm{i}}^{4}\right) \cdot \omega^{2}$

So the most efficient way to increase the energy stored in a flywheel is to speed it up. However, there is a problem with this solution, the materials that compose the wheel of that rotating system will limit the speed of the flywheel, due to the stress develop, called tensile strength, $\sigma$

Our target is achieve minimum flywheel dimension and weight using new material and to compare between different.

\section{MATERIAL SELECTION}

The most important issues of EMB's are the electrical machine used for energy conversion and material selection.

Motor/Generator used in spacecraft EMB is a variable high speed small machine with some limitations as thermal, heat transfer and mass. Flywheel is floated by magnetic bearings in EMB's. Therefore the magnets installed on rotor experience high temperature and its variations. The adequate material for this part is samarium-cobalt (Sm-Co) [8].

Because of the high electrical frequencies associated with machine operation, a high-frequency ferromagnetic "core" material was chosen for the stator and rotor. Core losses are particularly important in EMB, as they represent a constant power loss, relatively independent of the power output of the machine.

Different kinds of Ferromagnetic materials can be used in stator and rotor yokes design such as cobalt-iron alloys, non-oriented nickel-iron alloys, and amorphous metals.

Non-oriented nickel-iron alloy has electrical resistivity and saturation flux density approximately half that of amorphous iron. So it does not appear to be a viable candidate. Iron-cobalt alloy is often used to achieve high power density because of high saturation flux density, approximately 2.2 Tesla [9].

Table 1.Representative Electrical Properties of Soft Ferromagnetic Materials

\begin{tabular}{|c|c|c|c|}
\hline & $\begin{array}{c}\text { Iron-Cobalt } \\
\text { Alloy }\end{array}$ & $\begin{array}{c}\text { Non-oriented } \\
\text { Nickel-Iron }\end{array}$ & $\begin{array}{c}\text { Amorphous } \\
\text { Iron }\end{array}$ \\
\hline Bsat & $2.2 \mathrm{~T}$ & $0.7 \mathrm{~T}$ & $1.6 \mathrm{~T}$ \\
\hline $\mathrm{Hct}$ & $0.3 \mathrm{v} / \mathrm{m}$ & $0.02 \mathrm{v} / \mathrm{m}$ & $0.05 \mathrm{v} / \mathrm{m}$ \\
\hline$\rho$ & $25 \mu \Omega \mathrm{cm}$ & $57 \mu \Omega \mathrm{cm}$ & $130 \mu \Omega \mathrm{cm}$ \\
\hline $\mathrm{Tc}$ & $940^{\circ} \mathrm{C}$ & $460^{\circ} \mathrm{C}$ & $370^{\circ} \mathrm{C}$ \\
\hline
\end{tabular}

It is also desirable to keep flux densities low in the core material at high frequencies to keep core losses reasonable, thus the Benefits of the high saturation flux density of the iron-cobalt materials is not the main priorities. The electrical resistivity of amorphous iron is approximately 5 times higher than that of the iron-cobalt alloy, and its intrinsic coercively is lower by roughly a factor of 6 . For the rotor yoke, frequency properties of the material are less important, as the flux density in the rotor ideally DC, although some harmonics will exist due to the winding structure, current waveforms, and the slotting of the stator iron. However, if a laminated yoke is chosen, losses due to these harmonics would be negligible.
Table 2. Representative Mechanical Properties of Soft Ferromagnetic Material

\begin{tabular}{|c|c|c|}
\hline & $\begin{array}{c}\text { Iron-Cobalt } \\
\text { Alloy } \\
\text { (annealed) }\end{array}$ & Amorphous Iron \\
\hline Yield strength & $365 \mathrm{~N} / \mathrm{mm}^{2}$ & $999.7 \mathrm{~N} / \mathrm{mm}^{2}$ \\
\hline $\begin{array}{c}\text { Modulus of } \\
\text { Elasticity }\end{array}$ & $2 \times 108 \mathrm{~N} / \mathrm{m}^{2}$ & $1 \times 108 \mathrm{~N} / \mathrm{m}^{2}$ \\
\hline
\end{tabular}

A solid yoke would be preferable to a laminated yoke from a strictly structural standpoint because of its increased strength. However, the lower modulus of a laminated yoke has the benefit of reducing the maximum principal stresses in the magnets. Representative mechanical properties of laminated iron-cobalt and amorphous iron alloys are given in Table 2. Though their modulus elasticity is about half that of iron-cobalt, it was determined that amorphous material is also desirable for the rotor backiron, as their yield strength is about three times higher when compared to other annealed soft magnetic alloys.

In our design an amorphous iron alloy is used for high strength $(999.7 \mathrm{~N} / \mathrm{mm} 2)$ and suitable saturation flux densities.

The materials that compose flywheel's rotor [8], [9] will limit its rotational speed, due to the tensile strength developed.

Lighter materials develop lower inertial loads at a given speed, therefore composite materials, with low density and high tensile strength, are excellent for storing kinetic energy.

Table 3. Shows characteristics of several materials used on wheels. The analysis of the table confirms that the carbon composite materials will maximize the energy density. Composite materials are a new generation of materials that are lighter and stronger than the conventional ones, such as steel.

Carbon AS4C was chosen because it is the second best on tensile strength and on energy density while the first one (carbon T100) have higher weight (density) which may be a problem in satellite performance so carbon AS4C can achieve the required energy stored with optimal dimension (volume) and optimal weight.

Table 3. Characterizes of common rotor material

\begin{tabular}{|c|c|c|c|}
\hline Material & Density(Kg/m3) & $\begin{array}{c}\text { Tensile } \\
\text { Strength } \\
\text { (MPa) }\end{array}$ & $\begin{array}{c}\text { Max } \\
\text { energy } \\
\text { density(for } \\
\mathbf{1 ~ k g})\end{array}$ \\
\hline $\begin{array}{c}\text { Monolithic } \\
\text { material } \\
4340 \text { steel } \\
\text { composites }\end{array}$ & 7700 & 1520 & $0.19 \mathrm{MJ} / \mathrm{Kg}$ \\
\hline E-glass & 2000 & 100 & $0.05 \mathrm{MJ} / \mathrm{Kg}$ \\
\hline S-glass & 1920 & 1470 & $0.76 \mathrm{MJ} / \mathrm{Kg}$ \\
\hline $\begin{array}{c}\text { Carbon } \\
\text { T1000 }\end{array}$ & 1520 & 1950 & $1.28 \mathrm{MJ} / \mathrm{Kg}$ \\
\hline Carbon AS4C & 1510 & 1650 & $1.1 \mathrm{MJ} / \mathrm{Kg}$ \\
\hline
\end{tabular}

\section{PROPER STRUCTURE}

Kinetic energy stored in a flywheel is related by inertia and square of angular velocity, $\frac{1}{2} \mathrm{~m} \cdot \mathrm{r}^{2}$ is related by mass and square of flywheel radius then angular velocity and radius have to be as large as possible for volume and mass optimization. Finally proper structure for spacecraft EMB is a hollow cylinder with centered external rotor electrical machine. 
Another important parameter is machine number of pole [10], in this paper the number of poles for spacecraft EMB is chosen as four pole machine.

The most important part of EMB's is their Electrical machine used for energy conversion. Radial-flux Permanent Magnet (PM) machines are used in our design but there is more than one type of PM machines according to rotor configurations as follows:-

\subsection{Surface PM Machine}

Surface mounted permanent magnet (SMPM) is the most common rotor configuration for PM machines. The magnets are placed on the rotor surface. The magnets are glued onto the rotor surface and fixed by a carbon or glass fiber bandage. In relation to other PM concepts, the surface mounted machines are easy to manufacture and consequently the construction cost is low. The main drawback of these machines is the exposition of the permanent magnets to demagnetization fields. The magnets are also subject to high centrifugal forces. But at moderate peripheral speeds, the use of a glass fiber bandage is usually enough to withstand these forces. As the permeability of the magnets is almost the same as the permeability of air, the $\mathrm{d}$-axis and the q-axis reluctances are equal. Hence, the SMPM machines have no saliency and the torque is only produced by the interaction between the stator currents and the magnets [11].

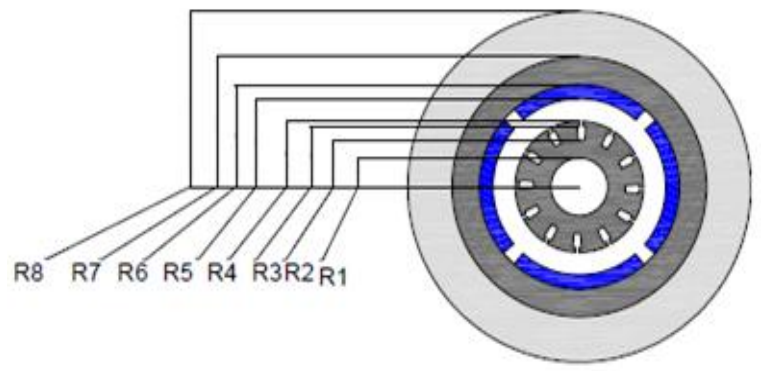

Fig 1 -the proposed surface PM machine

\subsubsection{Simplified Parametric Machine Design}

Parametric design will be done according to Fig (1). Permanent magnet machine design for EMB application consists of the flowing steps [12]:

1. Calculation of flux density functions in air gap.

2. Determination of current and number of turns according to the required torque and output voltage.

3. Determination of necessary Iron cross section in such that working point remains below the flux density saturation point.

4. Determination of outer radius to guarantee the necessary inertia and kinetic energy.

5. Find necessary slot space according to copper, insulators area and filling factor.

After solving Poisson's equation [4], [13] for the PM magnetic field in the polar coordinate system, the final solution for the radial air gap field is given by:

$\mathrm{B}_{\text {air } 1}(\mathrm{r}, \theta)=\sum_{\mathrm{n}=1}^{\infty}\left(\mathrm{M}_{\mathrm{n}} / \mu_{\mathrm{m}}\right)\left(\mathrm{np} / \mathrm{np}^{2}-1\right) \mathrm{R}_{5}^{-(\mathrm{np}-1)} \times$

$\left\{\frac{(\mathrm{np}-1) \mathrm{R}_{5}^{2 n p}+2 \mathrm{R}_{6}^{(\mathrm{np}+1)} \mathrm{R}_{5}^{(\mathrm{np}-1)}-(\mathrm{np}+1) \mathrm{R}_{6}^{2 n p}}{\mu_{\mathrm{m}}+1 / \mu_{\mathrm{m}}\left[\mathrm{R}_{4}^{2 \mathrm{np}}-\mathrm{R}_{6}^{2 n p}\right]-\mu_{\mathrm{m}}-1 / \mu_{\mathrm{m}}\left[\mathrm{R}_{5}^{2 n p}-\mathrm{R}_{4}^{2 n p}\left(\mathrm{R}_{6} / \mathrm{R}_{5}\right)^{2 \mathrm{np}}\right.}\right\} \times$

$\left[\mathrm{r}^{(\mathrm{np}-1)}+\mathrm{R}_{4}^{2 \mathrm{np}} \mathrm{r}^{-(\mathrm{np}+1)}\right] \cos (\mathrm{np} \theta)$
For radial magnetized PM:

$M_{n}=2 B_{r} \alpha_{p} \sin \left(n \pi \alpha_{p} / 2\right) /\left(n \pi \alpha_{p} / 2\right)$

Equation (6) is a complex series deeply depends on PM and air gap width.

Parametric design causes very complex using (6) in design equation taking $\mu \mathrm{m}=1, \mu \mathrm{r}=1$ where can be rewritten

$\mathrm{B}_{\mathrm{air} 2}=\mathrm{B}_{\mathrm{r}} \mathrm{L}_{\mathrm{m}} /\left(\mathrm{L}_{\mathrm{m}}+\mathrm{L}_{\mathrm{g}}\right)=\mathrm{B}_{\mathrm{r}}\left(\mathrm{R}_{6}-\mathrm{R}_{5}\right) /\left(\mathrm{R}_{6}-\mathrm{R}_{4}\right)$

for (6),(8) we consider

$\mathrm{Br}=1, \alpha \mathrm{p}=.66, \mu \mathrm{m}=1.05, \mathrm{p}=2, \mathrm{R}_{6}=20 \mathrm{~mm}, \mathrm{R}_{5}=18 \mathrm{~mm}, \mathrm{R}_{4}$ $=17 \mathrm{~mm}$ for fundamental component of magnetic flux density so $\mathrm{n}=1$ and $\mathrm{r}=\left(\mathrm{R}_{5}+\mathrm{R}_{4}\right) / 2$

$M_{n}=2 B_{r} \alpha_{p} \sin \left(n \pi \alpha_{p} / 2\right) /\left(n \pi \alpha_{p} / 2\right)$

From (6) $\mathrm{B}_{\text {air } 1}=0.691 \mathrm{~T}$

The equation (8) $\mathrm{B}_{\mathrm{air} 1}=0.67 \mathrm{~T}$

The difference between the values of $\mathrm{B}_{\mathrm{air} 1}$ for the simplified equations and the exact one is less than $5 \%$ which is acceptable for a simple design procedure. Considering independency of $\mathrm{B}_{\mathrm{air} 1}$, the overall force and phase-induced voltage can be determined by using $\mathrm{F}=\mathrm{L}$ I B and $\mathrm{E}=-\mathrm{l} \mathrm{V} B$ lows as follows [3], [14]:

$\mathrm{T}_{\mathrm{pm}}=\frac{3}{2} \psi \mathrm{i}$

$\mathrm{E}_{\mathrm{Pm}(\text { phase })}=\psi \omega$

$\psi=2 \mathrm{pNB}_{\mathrm{p}} \mathrm{K}_{\alpha} \mathrm{ZR}_{4}$

$\mathrm{K}_{\alpha}=\cos \left(\pi\left(1-\alpha_{\mathrm{p}}\right) / 2\right)$

Coil current and number of turns can be found according to machine torque and induced voltage.(9),(10)

$\omega=2093 \mathrm{~m} / \mathrm{s}$

$\mathrm{T}_{\mathrm{pm}}=23.8 \times 10^{-3} \mathrm{~N} . \mathrm{m}$

From $(10) \psi=6.61 \mathrm{mWb}$

So $\mathrm{i}=2.40 \mathrm{~A}$

Where $\mathrm{K} \alpha=0.8$

From (11) $\mathrm{N}=4.25$

According to $\mathrm{Fig}(1)$.

$\mathrm{R}_{\mathrm{p}}=\mathrm{R}_{\mathrm{t}}(2 \mathrm{p} / \mathrm{Nt})$

$\mathrm{R}_{\mathrm{t}}=\mathrm{N}_{\mathrm{t}}\left(\mathrm{R}_{6}-\mathrm{R}_{4}\right) / \mu_{0} \pi \mathrm{Z}\left(\mathrm{R}_{6}+\mathrm{R}_{4}\right)$

$\mathrm{Z}$ is considered equal $30 \mathrm{~mm}$, Nt equal to 12 , So For air gap reluctance; $\mathrm{R}_{\mathrm{t}}=5.8 \times 10^{6} \mathrm{~A} / \mathrm{Wb}$

And the air gap in front of pole

$\mathrm{R}_{\mathrm{p}}=\mathrm{R}_{\mathrm{t}} 2 \mathrm{p} / \mathrm{N}_{\mathrm{t}}=1.9 \times 10^{6} \mathrm{~A} / \mathrm{Wb}$

So the produced flux by coil and magnet can be calculated as:

$\Phi_{\text {coil }}=\mathrm{Ni} / \mathrm{R}_{\mathrm{t}}=1.74604 \times 10^{-6} \mathrm{~Wb}$

$\Phi_{\text {(magnet) }}=\mathrm{B}_{\mathrm{r}}\left(\mathrm{R}_{6}-\mathrm{R}_{5}\right) / \mu 0 \mathrm{R}_{\mathrm{t}}=244.247 \times 10^{-6} \mathrm{~Wb}$.

And maximum total flux of each part determined by:

$\Phi_{\text {total }}=1.5 \Phi_{\text {coil }}+\Phi_{\text {(magnet })}=2.46866 \times 10^{-4} \mathrm{~Wb}$

From working point below flux density saturation $1.4 \mathrm{~T}$ width of stator and rotor yoke, dent can be calculated as

$\mathrm{W}_{\mathrm{t}}=\Phi_{\text {total }} / \mathrm{Z} \mathrm{B}_{\max }=5.8 \times 10^{-3} \mathrm{~m}$

$\mathrm{W}_{\mathrm{t}}$ Should be at least equal to $5.8 \times 10^{-3} \mathrm{~m}$ so selecting

$\mathrm{Wt}=6.1 \times 10^{-3} \mathrm{~m}$

$\mathrm{R}_{2}=.0161$

$\mathrm{W}_{\mathrm{y}}=\frac{1}{2} \frac{\mathrm{N}_{\mathrm{t}}}{2 \mathrm{p}} \mathrm{Wt} \alpha=5.81 \times 10^{-3} \mathrm{~m}$ 
so we will consider the value of $\mathrm{W}_{\mathrm{y}}=6.810^{-3} \mathrm{~m}$

$\mathrm{R}_{7}=.0324$

Then the necessary slot space is:

$\mathrm{A}_{\mathrm{cu}}=12 \mathrm{pNiK}_{\mathrm{cu}} / \mathrm{N}_{\mathrm{t}} \mathrm{ff}$

Where

$\mathrm{Kcu}=5.622 \times 10^{-7} \mathrm{~m}^{2} / \mathrm{A}$

$\mathrm{ff}=0.6$

Acu $=19.19 \times 10^{-6} \mathrm{~m}^{2}$

On the other hand according to Fig I available slot space is:

$A_{s}=\pi\left(R_{3}^{2}-R_{2}^{2}\right) / N_{t}-W_{t}\left(R_{3}-R_{2}\right)$

By equalizing necessary and available space:

$\mathrm{As}=\mathrm{Acu}$

$\mathrm{R}_{3}^{2}-\left(\mathrm{N}_{\mathrm{t}} \mathrm{W}_{\mathrm{t}} / \pi\right) \mathrm{R}_{3}+\left(\mathrm{N}_{\mathrm{t}} \mathrm{W}_{\mathrm{t}} / \pi\right) \mathrm{R}_{2}-\mathrm{R}_{2}^{2}-\mathrm{A}_{\mathrm{cu}}\left(\mathrm{N}_{\mathrm{t}} / \pi\right)=0$

Solving (23) we get $R_{3}=0.021 \mathrm{~m}$

All machine dimensions is found except outer radius of flywheel. The kinetic energy stored on a hallow cylinder can be define as:

$\mathrm{E}=\mathrm{Pt}=\frac{1}{2} \mathrm{I}_{\text {total }}\left(\omega_{2}^{2}-\omega_{1}^{2}\right)$

$\mathrm{t}$ is equal (30 $\mathrm{min})$, the eclipse time expected in LEO satellite.

If $\mathrm{N} 1=20000 \mathrm{rpm} \quad$ min speed of flywheel

$\mathrm{N} 2=60000 \mathrm{rpm}$ max speed of flywheel

Considering a power load of our LEO satellite equal to 50 watt, the total energy required from the flywheel is $\mathrm{E}=90000$

From (18)\&(19)

$\mathrm{It}=5.135 \mathrm{~g} \cdot \mathrm{m}^{2}$

It $=$ Ipm + Ife + If

Now we can apply (4) for our design to determined the dimension of flywheel and achieve our target to minimize dimension, weight and used material.

Considering table 3. Carbon AS4C will be used as a material of the flywheel design.

$\mathrm{Ipm}=\frac{1}{2} \rho_{\mathrm{pm}} \mathrm{Z} \pi\left(\mathrm{R}_{3}^{4}-\mathrm{R}_{2}^{4}\right)$

Ife $=\frac{1}{2} \rho_{\mathrm{fe}} \mathrm{Z} \pi\left(\mathrm{R}_{4}^{4}-\mathrm{R}_{3}^{4}\right)$

If $=\frac{1}{2} \rho_{\mathrm{f}} \mathrm{Z} \pi\left(\mathrm{R}_{5}^{4}-\mathrm{R}_{4}^{4}\right)$

Where

$\rho_{\mathrm{pm}}=8400 \mathrm{~kg} / \mathrm{m}^{3}$ density of permanent magnet material

$\rho_{\mathrm{fe}}=7400 \mathrm{~kg} / \mathrm{m} 3$ density of ferromagnetic material

$\rho_{\mathrm{f}}=1510 \mathrm{~kg} / \mathrm{m} 3$ density of carbon epoxy material

so

$\mathrm{Ipm}=4.3 \times 10^{-05} \mathrm{Kg} \cdot \mathrm{m} 2$

Ife $=2.3 \times 10^{-04} \mathrm{Kg} \cdot \mathrm{m}^{2}$

If $=$ It - Ipm - Ife $=4.857$ g. $\mathrm{m}^{2}$

$\mathrm{R}_{8}=0.0913 \mathrm{~m}$

Applying (4) and using carbon AS4C material for flywheel the radius of flywheel decrease from $0.135 \mathrm{~m}$ in [3] to .0913 $\mathrm{m}$ in this paper which saves $47 \%$ of the overall dimension, this help decreasing satellite weight and dimension.
TABLE 4. Design Results for surface Pm machine

\begin{tabular}{|c|c|c|c|c|}
\hline $\mathbf{R}_{\mathbf{1}}$ & $\mathbf{R}_{\mathbf{2}}$ & $\mathbf{R}_{\mathbf{3}}$ & $\mathbf{R}_{\mathbf{4}}$ & $\mathbf{R}_{\mathbf{5}}$ \\
\hline 10 & 16.1 & 21.3 & 22.8 & 23.8 \\
$\mathrm{~mm}$ & $\mathrm{~mm}$ & $\mathrm{~mm}$ & $\mathrm{~mm}$ & $\mathrm{~mm}$ \\
\hline $\mathbf{R}_{\mathbf{6}}$ & $\mathbf{R}_{\mathbf{7}}$ & $\mathbf{R}_{\mathbf{8}}$ & $\mathbf{N t}$ & $\mathbf{A c u}$ \\
\hline 25.6 & 32.4 & 91.3 & 12 & 19.19 \\
$\mathrm{~mm}$ & $\mathrm{~mm}$ & $\mathrm{~mm}$ & & $\mathrm{~mm}^{2}$ \\
\hline
\end{tabular}

\subsection{Inset PM Machines}

In inset PM machines, the magnets are mounted on the rotor surface as shown in figure 2. But the magnets are sunken in the rotor core, offering better protection than in a SMPM machine. However, a bandage is often required in order to withstand the centrifugal forces.

The same numerical calculation as before from equation 1 to 28 and the same dimensions of the machine, the machines have q-axis reluctance is lower than the d-axis reluctance due to the iron between the magnets. This is known as salient poles. Due to the saliency, reluctance torques is created in addition to the torque from the magnets and high surface loss density .The machine will has both higher rated torque and higher max torque

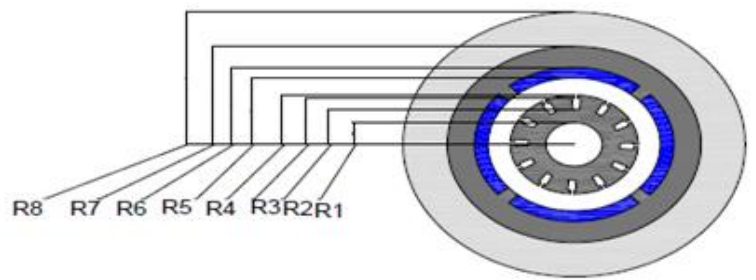

Fig. 2.The proposed Inset Pm machine.

Table 5. Design Result for Inset Pm machine

\begin{tabular}{|c|c|c|c|c|}
\hline $\mathbf{R}_{\mathbf{1}}$ & $\mathbf{R}_{\mathbf{2}}$ & $\mathbf{R}_{\mathbf{3}}$ & $\mathbf{R}_{\mathbf{4}}$ & $\mathbf{R}_{\mathbf{5}}$ \\
\hline 10 & 16.1 & 21.3 & 22.8 & 23.8 \\
$\mathrm{~mm}$ & $\mathrm{~mm}$ & $\mathrm{~mm}$ & $\mathrm{~mm}$ & $\mathrm{~mm}$ \\
\hline $\mathbf{R}_{\mathbf{6}}$ & $\mathbf{R}_{\mathbf{7}}$ & $\mathbf{R}_{\mathbf{8}}$ & $\mathbf{N t}$ & Acu \\
\hline 25.6 & 32.4 & 91.3 & 12 & 19.19 \\
$\mathrm{~mm}$ & $\mathrm{~mm}$ & $\mathrm{~mm}$ & & $\mathrm{~mm}^{2}$ \\
\hline
\end{tabular}

As we can see in Fig2, 1 that both design of surface permanent magnet machine and Inset permanent magnet machine gives the same dimensions because they have the same configuration and only varied in their own permanent magnet position

\subsection{Buried PM machines}

Another PM concept is to bury the magnets in the rotor core. This is referred to as buried PM machines. The magnets are better protected against demagnetization fields and mechanical stress. There are many different possibilities for the placement of magnets in the rotor. The magnets can be placed in such a way that the flux generated by the magnets in the rotor is concentrated and thus higher air gap flux densities can be achieved, Fig(3).

The same numerical calculation as before from equation 1 to 28 except equation 8 do not apply and the same dimension of the machine, the machine has salient poles due to buried PM machines so reluctance torque is created. A main drawback of the buried PM machines is the difficulty of manufacturing process, thus the high production cost. The machines have low rated torque, low max torque and low rated power but the machine has low surface density and higher efficiency . 


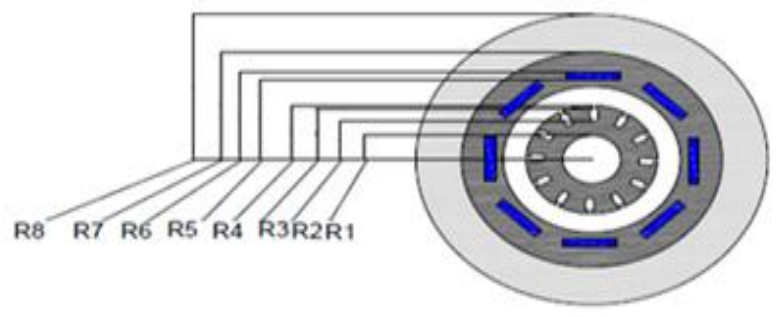

Fig. 3. The proposed Buried Pm machine.

Table 6. Design Result for the buried Pm machine

\begin{tabular}{|c|c|c|c|c|}
\hline $\mathbf{R}_{\mathbf{1}}$ & $\mathbf{R}_{\mathbf{2}}$ & $\mathbf{R}_{\mathbf{3}}$ & $\mathbf{R}_{\mathbf{4}}$ & $\mathbf{R}_{\mathbf{5}}$ \\
\hline $\begin{array}{c}10 \\
\mathrm{~mm}\end{array}$ & $\begin{array}{c}16.1 \\
\mathrm{~mm}\end{array}$ & $\begin{array}{c}21.3 \\
\mathrm{~mm}\end{array}$ & $\begin{array}{c}22.8 \\
\mathrm{~mm}\end{array}$ & $\begin{array}{c}27.6 \\
\mathrm{~mm}\end{array}$ \\
\hline $\mathbf{R}_{\mathbf{6}}$ & $\mathbf{R}_{\mathbf{7}}$ & $\mathbf{R}_{\mathbf{8}}$ & $\mathbf{N}_{\mathbf{t}}$ & $\mathbf{A c u}$ \\
\hline 28.6 & 32.4 & 91.3 & 12 & $\begin{array}{c}19.19 \\
\mathrm{~mm}\end{array}$ \\
$\mathrm{~mm}$ & $\mathrm{~mm}$ & $\mathrm{~mm}$ & & \\
\hline
\end{tabular}

Comparing of tables 6 and both of table 5, 4 we can see the change in $R_{5}, R_{6}$ due to the position of permanent magnet

\subsection{Halbach Array machine}

A Halbach array is a special arrangement of permanent magnets that augments the magnetic field on one side of the array while cancelling the field to near zero on the other side this is achieved by having spatially rotating pattern of magnetization as Fig(4).

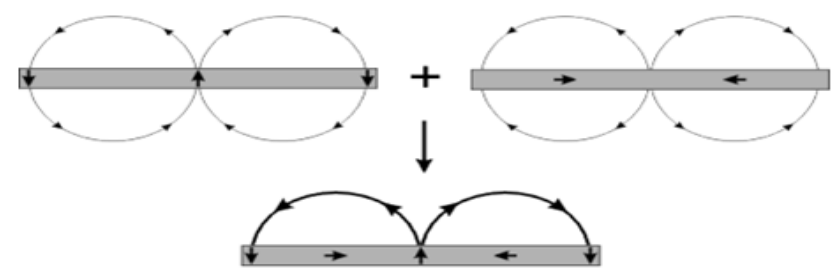

Fig. 4.Magnetic Field distribution on Halbach array machine

A fundamental advantage of a machine of this type has already been mentioned [15]. The machine can be constructed without the use of magnetic material other than the permanent magnets. There is no need for laminations or back iron. It has two major advantages. First the conventional core loss and eddy current loss in the laminations or back iron does not exist. The only loss in the machine will be losses in the windings. The second advantage is since there is no back iron or laminations required, the machine is inherently lightweight

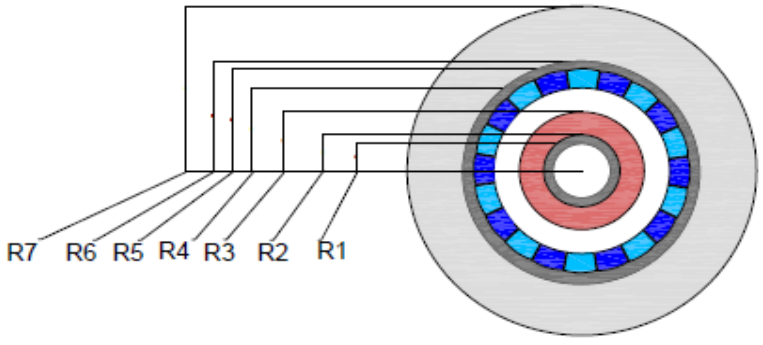

Fig. 5. The proposed Halbach Array machine

For numerical dimension design and solving Poisson's equation [4],[13] for the PM magnetic field in the polar coordinate system, solution for the radial air gap field is given by:
$\mathrm{B}_{\mathrm{air}}=\left(-\mathrm{B}_{\mathrm{r}} \mathrm{p} / 1-\mathrm{p}\right) \times \frac{1-\left(\frac{\mathrm{R}_{2}}{\mathrm{R}_{5}}\right)(\mathrm{p}-1)}{1-\left(\frac{\mathrm{R}_{2}}{\mathrm{R}_{5}}\right)(2 \mathrm{p})} \times\left(1-\left(\mathrm{R}_{2} / \mathrm{r}\right)^{2 \mathrm{p}}\right) \times$

$\left(\mathrm{r} / \mathrm{R}_{4}\right)^{(\mathrm{p}-1)} \times \cos (\mathrm{p} \theta)$

Steps of design as before except 13 to 19 because it does not need magnetic material so rotor and stator yoke equal zero but $1 \mathrm{~mm}$ thickness is chosen for the mechanical considerations.

Table 7. Given parameter for machine design

\begin{tabular}{|c|c|c|c|c|c|c|}
\hline $\mathbf{P}$ & $\mathbf{T}$ & N1 & N2 & El-I & ff & $\begin{array}{c}\text { Bma } \\
\mathbf{x}\end{array}$ \\
\hline $50 \mathrm{w}$ & $\begin{array}{l}1800 \\
\text { sec }\end{array}$ & $\begin{array}{c}20 \\
\text { Krpm }\end{array}$ & $\begin{array}{c}60 \\
\text { Krpm }\end{array}$ & $\begin{array}{c}24 \\
\mathrm{v}\end{array}$ & .6 & $\begin{array}{c}1.4 \\
\mathrm{~T}\end{array}$ \\
\hline $\mathbf{N t}$ & $\mathbf{N p}$ & Lg & Im & $\mathbf{Z}$ & $\alpha$ & $\mathrm{Br}$ \\
\hline 12 & 4 & $\begin{array}{c}1 \\
\mathrm{~mm}\end{array}$ & $\begin{array}{c}2 \\
\mathrm{~mm}\end{array}$ & $\begin{array}{l}30 \\
\mathrm{~mm}\end{array}$ & $\begin{array}{l}.6 \\
6 \\
\end{array}$ & $\begin{array}{l}1 \\
\mathrm{~T}\end{array}$ \\
\hline $\boldsymbol{\mu 0}$ & Kcu & $\rho p m$ & $\rho f e$ & pcom & & \\
\hline $\begin{array}{c}.4 \Pi * 10 \\
-6\end{array}$ & $\begin{array}{c}5.622 * 10 \\
-7 \mathrm{~m} 2 / \mathrm{A}\end{array}$ & $\begin{array}{c}8400 \\
\mathrm{~kg} / \mathrm{m} \\
3\end{array}$ & $\begin{array}{c}7400 \\
\mathrm{~kg} / \mathrm{m} \\
3\end{array}$ & $\begin{array}{c}1510 \\
\mathrm{~kg} / \mathrm{m} \\
3\end{array}$ & & \\
\hline
\end{tabular}

\section{ADVANTAGES AND DISADVANTAGES OF THE PROPOSED MACHINE}

The advantages of surface PM machine is easy to manufacture, the $d$-axis and $q$ axis reluctance are equal so only the useful torque is produced by the interaction between the stator currents and the magnets only the disadvantages are high

Centrifugal force in PM but using glass fiber bondage help to withstand these forces.

-The advantage of inset PM machine is that for the same dimension the surface of PM can withstand the centrifugal force due to the position of sunken in the rotor core. Also it has higher rated torque and sustain a higher max torque [16] The disadvantage is the differences of $\mathrm{d}$ and q-axis which make salient pole (reluctance torque) and produces high surface loss.

- The advantage of buried PM machine is that for the same dimension of surface PM machine are better protected against demagnetization on field and machine stress due to the placement of magnet in the rotor yoke, the disadvantage is the salient pole which creates reluctance torque, the high production cost, the low rated torque and low rated power.

- Halbach array machine has different configuration due to the principle of operation, it has different methodology and different dimension which lead to minimum core loss, eddy current and only loss is winding.

From the analysis of this paper the choice between the four different designs depends on:-

-if the machine has high centrifugal force and high rated torque but it has enough ventilation to overcome surface losses, then inset PM machine will be the choice .

-if the target is high efficiency with low ventilation and low torque, then Buried PM machine will be the choice.

-if losses are the critical problem with the small volume, then Halbach array machine is the choice. 
-finally if the required machine has low cost and easy to manufacture with reluctance torque at high speed then surface mount PM with glass fiber bandage is the choice

\section{CONCLUSION}

The Design of an external rotor permanent magnet machine used in spacecraft electro-mechanical batteries is presented in this paper. This machine is required to supply a load of 50 watt for 30 minutes, the expected time of eclipse for LEO Satellite.

Samarium-cobolt is selected in the design of PM material for thermal and volume decrease, amorphous iron is used as ferromagnetic material because of its high strength (999 $\mathrm{N} / \mathrm{mm} 2$ ) to withstand high centrifugal force at high speed, Also the use of carbon AS4C as flywheel material to decrease the flywheel radiu $1 \mathrm{~s}$ by about $47 \%$ from $0.135 \mathrm{~m}$ [3] to 0.0913 $\mathrm{m}$ have been selected in this paper .This result in decreasing the satellite weight and volume of the proposed satellite electromechanical batteries.

Carbon glued or glass fiber bandage are used for Surface mounted permanent magnet helps to overcome the problem of centrifugal force.

\section{REFERENCE}

[1] G.E. Rodriguez, P.A. Studer, D.A. Baer, "Assessment of Flywheel Energy Storage for Spacecraft Power Systems", NASA Technical Memorandum, May 1983.

[2] M. R. Patel , " spacecraft power system ",first edition ,CRC press , 2005.

[3] Bolund, Bjorn; Bernhoff, Hans; Leijon, Mats; "Flywheel Energy and Power Storage Systems", Renewable and Sustainable Energy Reviews 11, pp 235-258, 2007.

[4] Abdi, J. Milimonfared, J. S. Moghani "Simplified design of PM Machine for spacecraft Elect Electro Mechanical Batteries ". S. Moghani,5th IET International Conference on Power Electronics, Machines and Drives 2010.

[5] M. A. Arslan, "Flywheel geometry design for improved energy storage using finite element analysis", ELSEVIER Transaction on material and design, 2007.

[6] W. Wang, "Design of High Speed Flywheel Motor/Generator for Aerospace Applications", PhD Thesis, The Pennsylvania State University, 2003.
[7] A.S. Nagorny, N.V. Dravid, R.H Jansen, B.H. Kenny, "Design Aspect of a High Speed Permanent Magnet Synchronous Motor/Generator for Flywheel Applications", IEEE Conference, 2005.

[8] J.A. Kirk, P.A. Studer, "Flywheel Energy Storage" Int. J. mech. Sci., VoL 19, pp. 233-245. Pergamon Press 1977.

[9] A. J.Rodrigues ," Design and Control of an Electrical Machine for Flywheel Energy- Storage System" Master in Electrical and Computer Engineering ,Maria Inês Lopes Marques.

[10] D. M. Ionel, M. Popescu, M. I. McGilp, T. J. E. Miller, S. J. Dellinger, "Assessment of Torque Components in Brushless Permanent-Magnet Machines Through Numerical Analysis of the Electromagnetic Field", IEEE Transaction on Industry Applications, VOL. 41, NO. 5, 2005. (17)

[11] A.Stening , "Design and optimization of a surfacemounted permanent magnet synchronous motor for a high cycle industrial cutter ", Master in Electrical and Computer Engineering, Royal Institute of Technology , Stockholm ,2006.

[12] J. F. Gieras, M. Wing, "Permanent Magnet Motor Technology, Design and Applications", Second edition, Marcel Dekker, 2002.

[13] S. R. Holm, H. Polinder, J. A. Ferreira, "Analytical Modeling of a Permanent-Magnet Synchronous Machine in a Flywheel", IEEE Transaction on Magnetics, VOL. 43, NO. 5, MAY 2007.

[14] B. Abdi, J. Milimonfared, J. S. Moghani , A. K. KAVIANI, "Simplified Design and Optimization of Slotless Synchronous PM Machine for Micro-Satellite Electro-Mechanical Batteries" ,5th IET International Conference on Power Electronics, Machines and Drives 2010.

[15] S. M. Jang, S. S. Jeong, D.W. Ryu, S.K. Choi, "Design and Analysis of High Speed Slotless PM Machine with Halbach Array", IEEE Transaction on Magnetics, VOL. 37, NO. 4, JULY 2001.

[16] T. Finken, M. Hombitzer , K. Hameyer " Study and comparison of several permanent-magnet excited rotor types regarding their applicability in electric vehicles ", Emobility - Electrical Power Train Conference, 2010 